\title{
A Study on Control of Interconnection Inverter with FRT and Islanding Detection Functions
}

\author{
Shoji Kawasaki and Masahiro Ise \\ Department of Electronics and Bioinformatics, School of Science and Technology, Meiji University, Kanagawa 214-8571, Japan
}

\begin{abstract}
In this study, the authors aim to develop the interconnection inverter of PV (photovoltaic generation) system with FRT (fault ride thorough) function and islanding detection function, and analyze the interaction between the both functions during the momentary voltage drop by using an analytical model of distribution system interconnected plural PV systems. Moreover, the authors propose a cooperated control method of the inverters with the islanding detection function and FRT function, and carry out a numerical calculation in order to verify the validity of the proposed method.
\end{abstract}

Key words: Interconnection inverter, islanding, islanding detection function, momentary voltage drop, FRT function.

\section{Introduction}

In recent years, for a global warming prevention and breakaway from fossil energy resources dependence, the introduction of the renewable energy progresses worldwide. Particularly, the introduction of the PV (photovoltaic generation) has been spreading in Japan [1]. The PV system is composed of the interconnection inverter and solar panel. However, there is a possibility that the problem of frequency or voltage occurs to an electric power system by widespread of PVs in the future [2]. When an accident occurs in the electric power system and the distributed generation is paralleled off from electric power system, it becomes islanding. Since there are the problems on preservation of the electric power system when it is in a condition of islanding, it is necessary to prevent islanding. Therefore, the inverters are provided with an islanding detection function. On the other hand, if PV systems are paralleled off by this function when the momentary voltage drop occurs by an accident such as thunderbolt, demand-supply balance of the electric power system collapses and it might become the massive blackout. Therefore, recent years, it has been developed the

Corresponding author: Shoji Kawasaki, associate professor, Eng. Dr., research fields: advancement of electric power system, improvement of electric power quality. inverter with an FRT (fault ride thorough) function to continue outputting during the momentary voltage drop.

In this study, the authors propose a cooperated control method of the inverter with FRT function and the frequency change rate detection method which is one of the islanding detection functions. The frequency change rate detection method is used in the previous study [3]. The detection system sends an off-signal to the inverter when frequency change rate exceeds the threshold in succession to avoid unnecessary stop. In this study, in addition, the authors verify the usefulness of the proposed control method by the numerical simulation using a distribution system model interconnected plural PV systems.

\section{Islanding Detection Function}

\subsection{Frequency Change Rate Detection Method}

This section describes the frequency change rate detection method which is one of the passive methods of islanding detection [4]. Fig. 1 shows the control block of frequency change rate detection method. The method senses a sudden change of frequency of grid voltage by accidents. When the frequency of voltage changes suddenly and the frequency change rate $\Delta f$ exceeds the threshold $f_{0}$, the PV system is paralleled 
off. The standard of the threshold is $\pm 0.1 \% \sim \pm 0.3 \%$.

\subsection{Frequency Feedback and Step-Injection Method}

This section describes the frequency feedback and step-injection method which is one of the active methods of islanding detection $[4,5]$. Fig. 2 shows the control block of frequency feedback and step-injection method. This method has two functions, the frequency feedback part and step-injection part. And the reactive current $I_{d}$ is injected by these two parts when the frequency changes suddenly.

Fig. 3 shows the characteristics of frequency deviation - reactive power of frequency feedback part [6]. In the frequency feedback part, when the frequency changes suddenly, the reactive power is injected rapidly in the direction that promotes a change of frequency. As shown in Fig. 3, the amount of injected reactive power is decided depending on the amount of change of frequency.

On the other hand, when the change of frequency is small (within $\pm 0.01 \mathrm{~Hz}$ ) and the harmonic voltage and the fundamental voltage is changed, the reactive power in the direction in which the frequency decreases is injected by the step-injection part as shown in Figs. 4 and 5 .
In this method, since the reactive power is injected in the direction that promotes a change of frequency, there is not mutual interference when plural PV systems are interconnected. And since the reactive power is injected depend on change of frequency; PV systems do not give the influence to the electric power system.

\section{FRT Function}

Recent years, it has been developed the inverter with FRT function that continues outputting during the momentary voltage drop. This chapter describes the FRT requirement and proposed control method of FRT function.

\subsection{FRT Requirement}

Fig. 6 shows the FRT requirement of the voltage reduction tolerated dose [7]. If the residual voltage is over $20 \%$ and the duration of voltage drop is within $1.0 \mathrm{sec}$, the inverter is required to continue outputting.

Fig. 7 shows the FRT requirement of the frequency variation tolerated dose for step variation. Even if the frequency increases stepwise, the inverter is required to continue outputting when the rise is less than $50.8 \mathrm{~Hz}$.

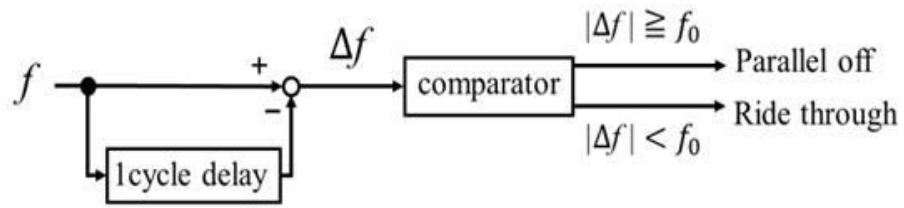

Fig. 1 Control block of frequency change rate detection.

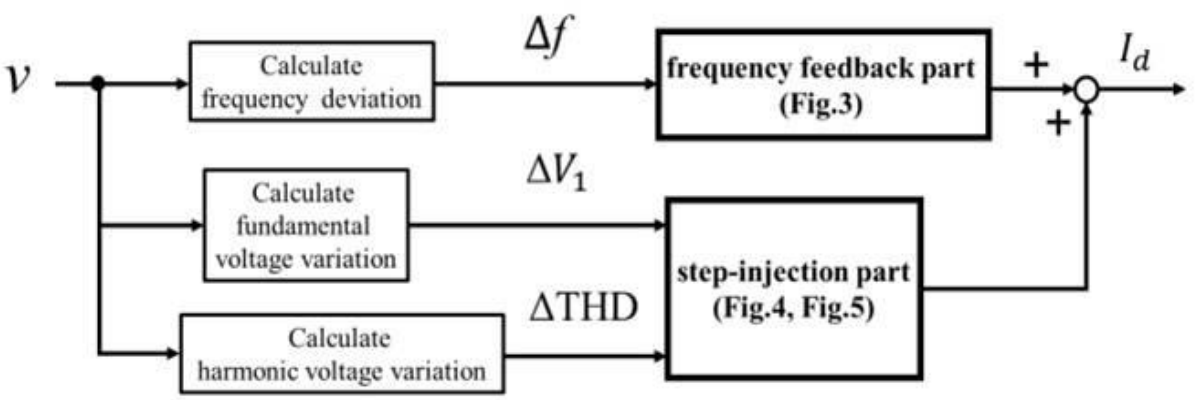

Fig. 2 Control block of frequency feedback and step-injection. 


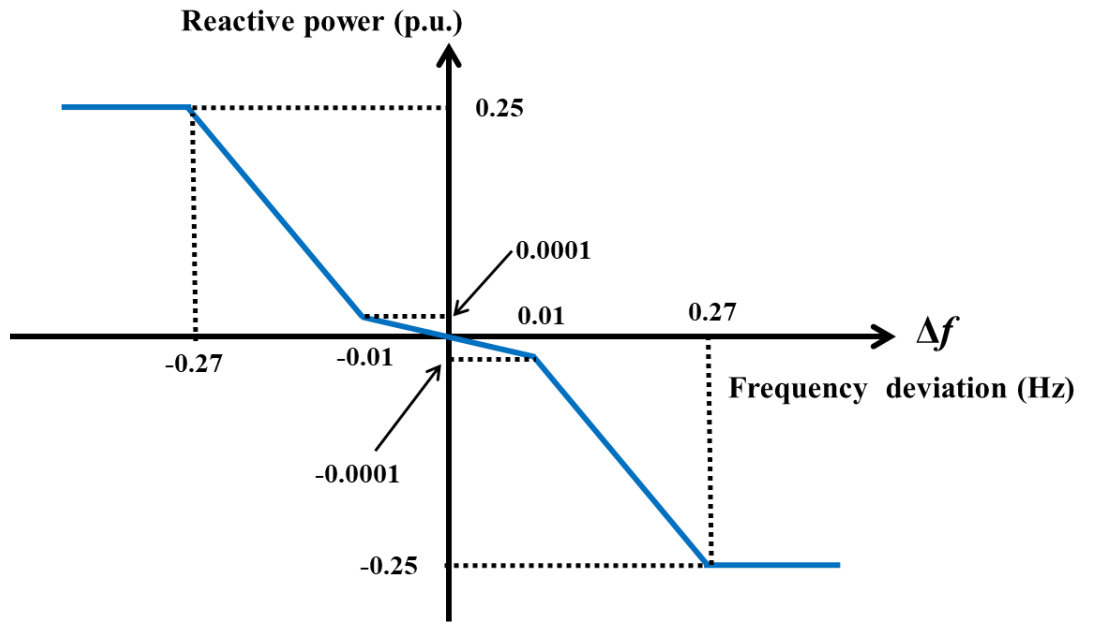

Fig. 3 Characteristics of frequency deviation - reactive power of frequency feedback part.

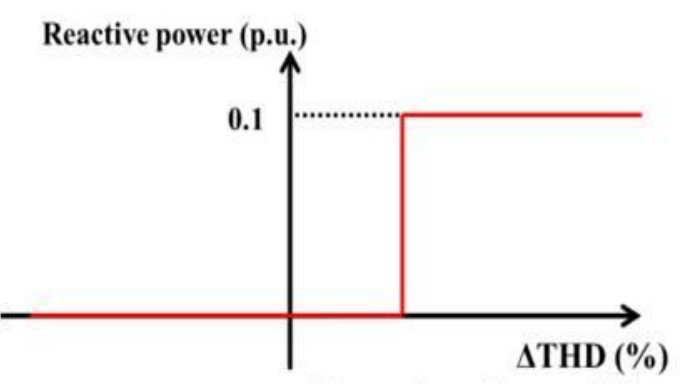

Harmonics voltage variation

Fig. 4 Step-injection in case of harmonic voltage variation.

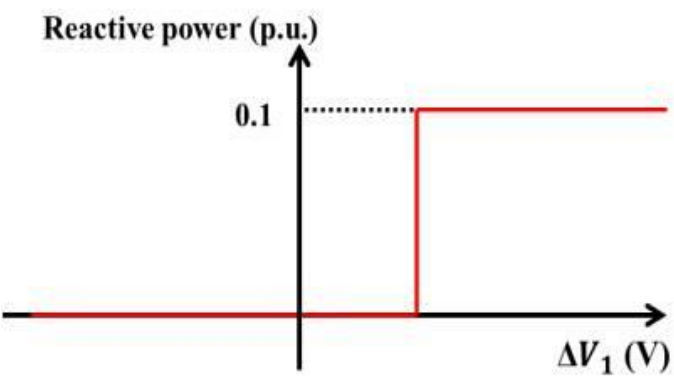

Fundamental voltage variation

Fig. 5 Step-injection in case of fundamental voltage variation.

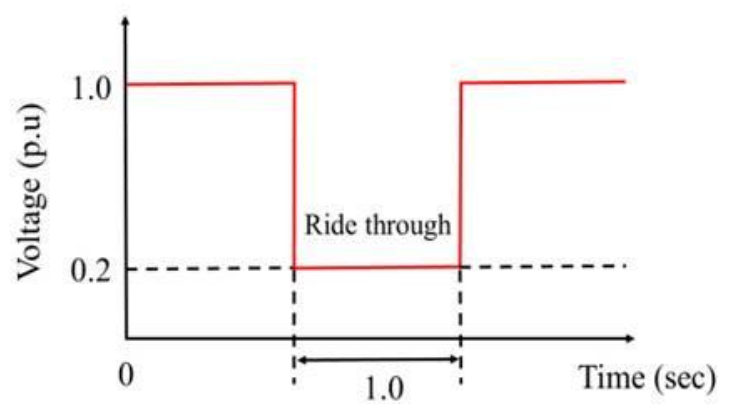

Fig. 6 Voltage reduction tolerated dose.

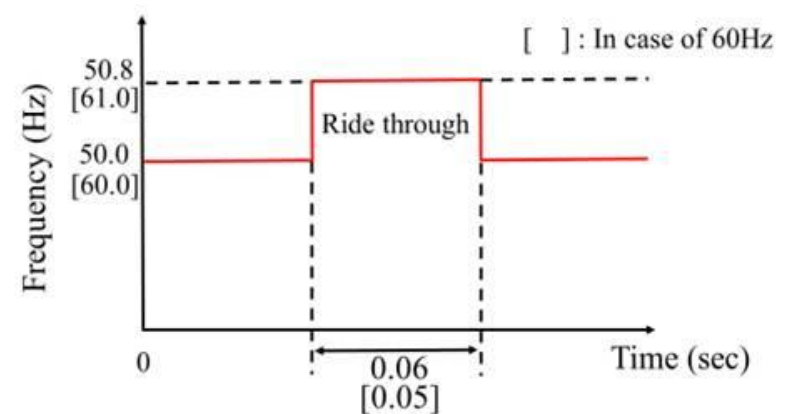

Fig. 7 Frequency variation tolerated dose (for step variation).

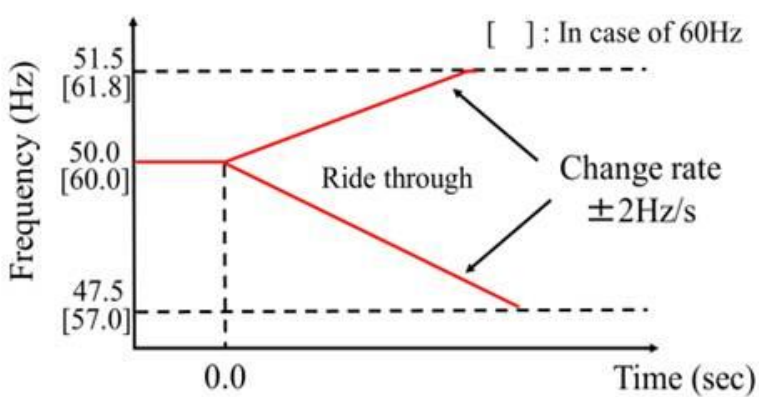

Fig. 8 Frequency variation tolerated dose (for ramp variation).

Fig. 8 shows the FRT requirement of the frequency variation tolerated dose for ramp variation. Even if the frequency increases, the inverter is required to continue outputting when the frequency change rate is less than $\pm 2 \mathrm{~Hz} / \mathrm{s}$.

\subsection{FRT Control Logic}

When it becomes islanding, the frequency increases as shown in Fig. 9 by the reactance of load and by the 


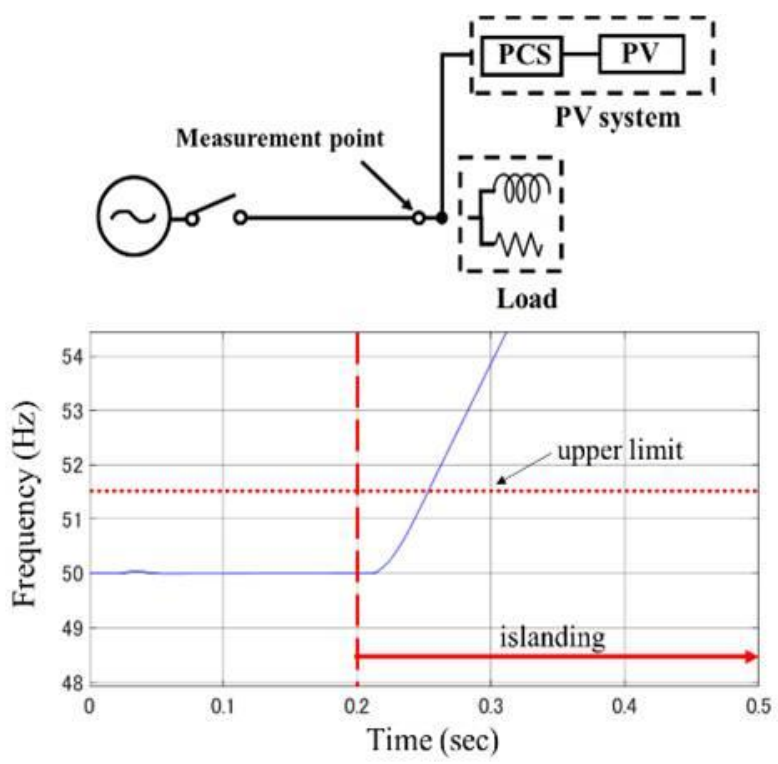

Fig. 9 Image of frequency fluctuation during islanding.

frequency feedback and step-injection method. On the other hand, when the momentary voltage drop occurs, the frequency fluctuates for a brief time as shown in Fig. 10. If the inverter is carried with the frequency change rate detection method, PV system is paralleled off when the frequency increases like Fig. 9 or when the frequency fluctuates like Fig. 10, even though PV system must ride through.

Fig. 11 shows the control block of proposed FRT function and Fig. 12 shows the cooperated control block of islanding detection and FRT function. The authors propose the FRT function that avoids unnecessary stop during the momentary voltage drop. First, the larger threshold is set for the frequency change rate $( \pm 0.6 \%( \pm 0.3 \mathrm{~Hz}))$. And send an off-signal to the inverter when the frequency change rate $\Delta f$ exceeds the threshold $f_{1}$ consecutively from the standard value of frequency $f_{r}(50 \mathrm{~Hz}$ or $60 \mathrm{~Hz})$ and the number of frequency change continuation cycle $N$

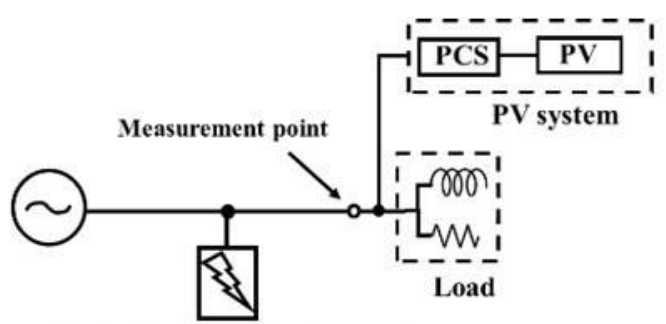

Short circuit accident generator

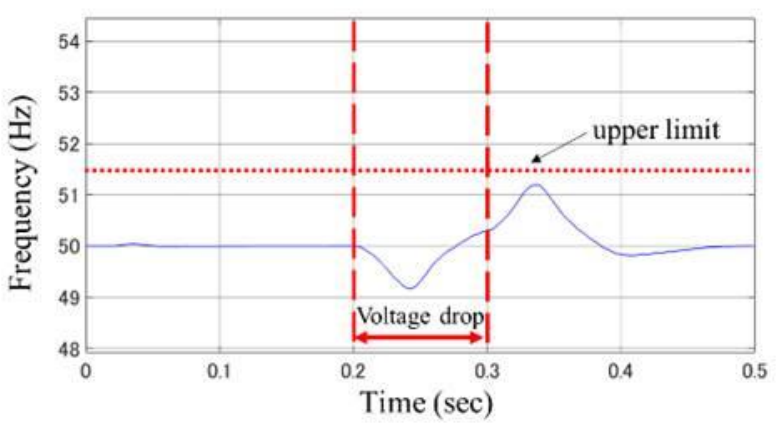

Fig. 10 Image of frequency fluctuation during momentary voltage drop.

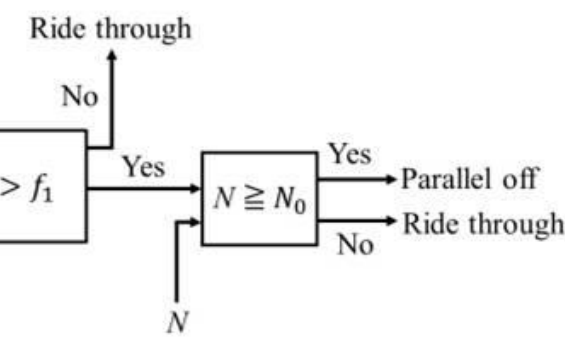

Fig. 11 Control block of proposed FRT function.

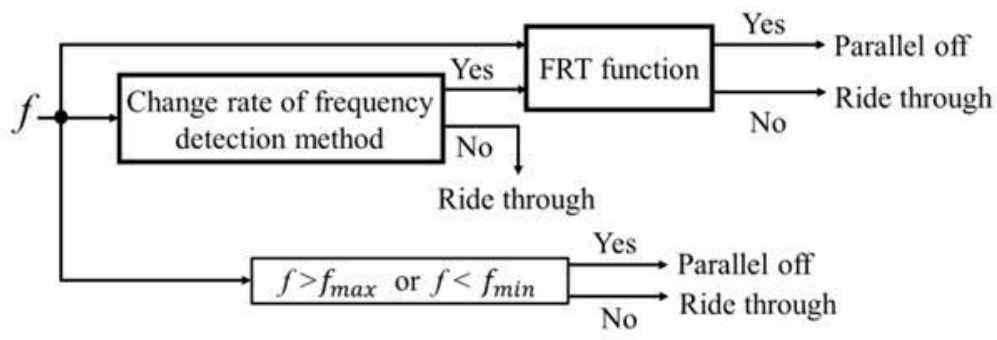

Fig. 12 Cooperated control block of islanding detection and proposed FRT function. 
exceeds the threshold $N_{0}$. Hence, in the inverter which is carried by the proposed cooperated control method, PV system is paralleled off when the frequency keeps increasing or decreasing. And when the frequency exceeds the setting value of over frequency relay $f_{\max }$ or the settingvalue of under frequency relay $f_{\text {min }}, \mathrm{PV}$ system is paralleled off.

\section{Numerical Calculation Example}

\subsection{Analytical Model of Distribution System and Simulation Condition}

The authors carry out the numerical calculations in order to verify the validity of the proposed method. Fig. 13 shows the analytical model of distribution system. The PV system and load are interconnected in the low-voltage distribution system. The momentary voltage drop will occur due to the short circuit accident. The islanding will occur due to separating from high-voltage system. The load capacity of consumer is $1 \mathrm{~kW}$. The output of PV is $1 \mathrm{~kW}$. The impedance of distribution lines is shown in Table 1 [8]. Fig. 14 shows the analytical model of distribution system in which plural PV systems are interconnected. The condition of load capacity, output of PV, and impedance of distribution lines are the same as the condition of Fig. 13.

\subsection{Simulation Results}

Firstly, the authors carried out the numerical calculations in case of PV system without FRT function and in case of PV system with the proposed FRT function, using the analytical model of Fig. 13. Figs. 15-17 show the simulation results in case of PV system without FRT function during the momentary voltage drop. Figs. 18-20 show the simulation results in case of PV system with the proposed FRT function during the momentary voltage drop. As shown in Figs. 15-17, in case of PV system without FRT function, PV system was paralleled off during the momentary voltage drop by the frequency change rate detection method and the output of PV became zero. On the other hand, in case of PV system with the proposed FRT function, PV system rode through (see Fig. 19).

Figs. 21-23 show the simulation results in case of PV system with the proposed FRT function during the islanding. In case of PV system with the proposed FRT function, since the frequency exceeded the setting value of over frequency relay $f_{\max }$ during the islanding, PV system was paralleled off and the output of PV became zero (see Figs. 21-23).

Secondly, the authors carried out the numerical calculation in case of interconnection of the plural PV

Table 1 Impedance of distribution lines.

\begin{tabular}{llll}
\hline & Unit & Resistance & Reactance \\
\hline High voltage wire & Ohm $/ \mathrm{km}$ & 0.0616 & 0.1504 \\
Low voltage wire & $\mathrm{Ohm} / \mathrm{km}$ & 0.2638 & 0.2438 \\
\hline
\end{tabular}

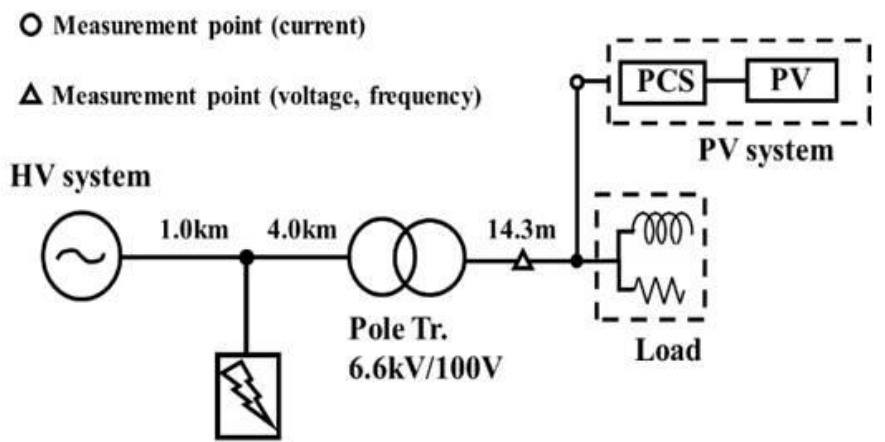

Short circuit accident generator

Fig. 13 Analytical model of distribution system. 


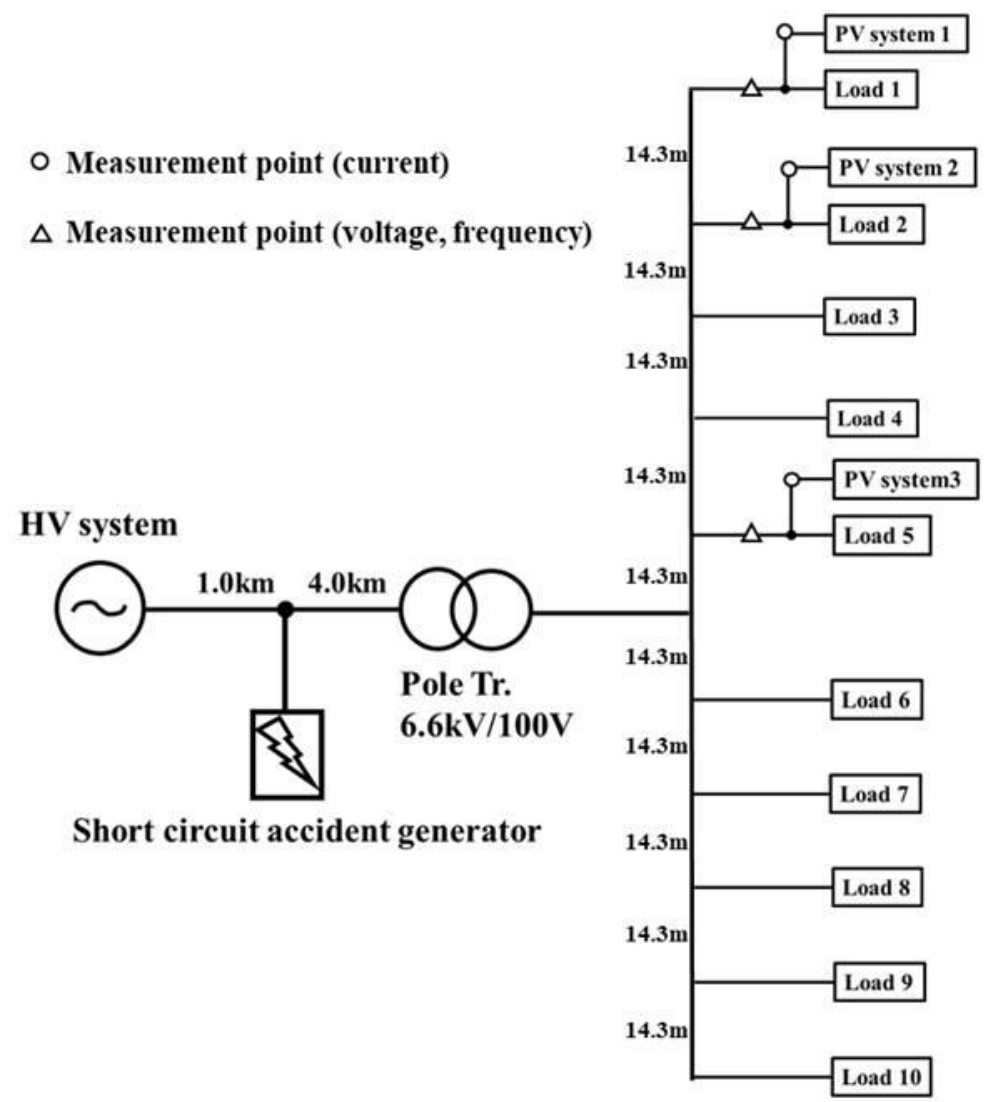

Fig. 14 Analytical model of distribution system interconnected plural PV systems.

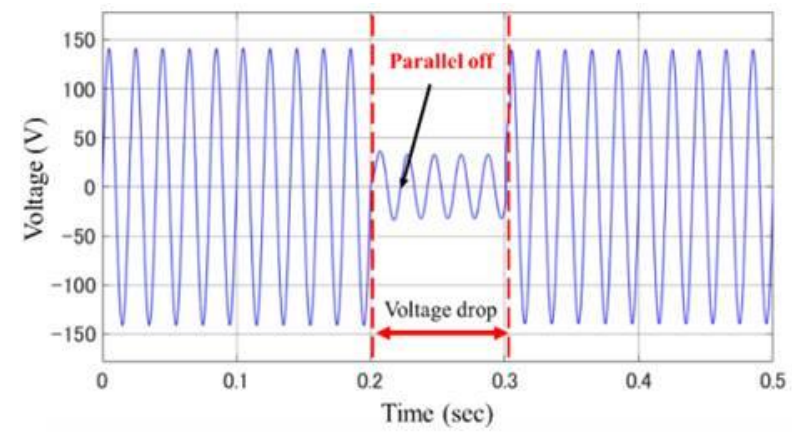

Fig. 15 Voltage variation during momentary voltage drop without FRT function.

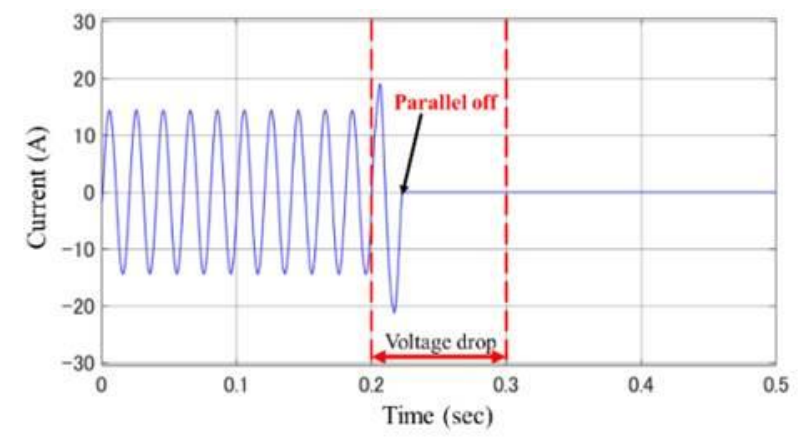

Fig. 16 Current variation during momentary voltage drop without FRT function.

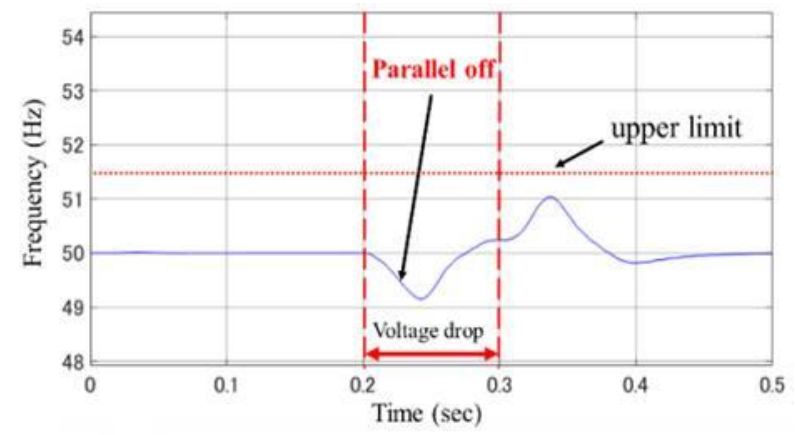

Fig. 17 Frequency variation during momentary voltage drop without FRT function.

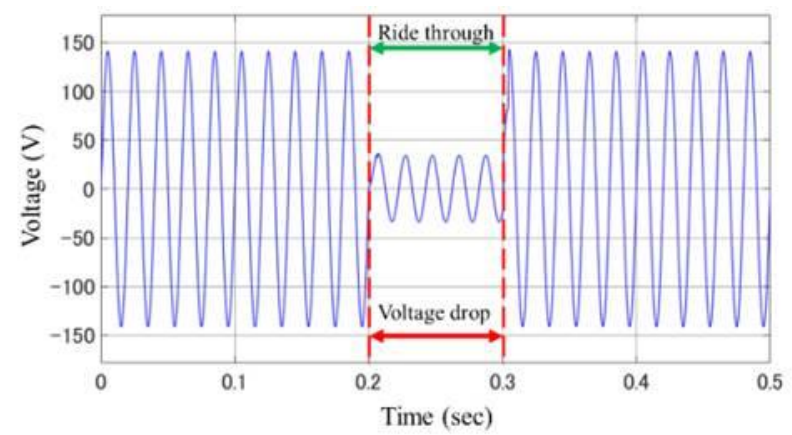

Fig. 18 Voltage variation during momentary voltage drop with proposed FRT function. 


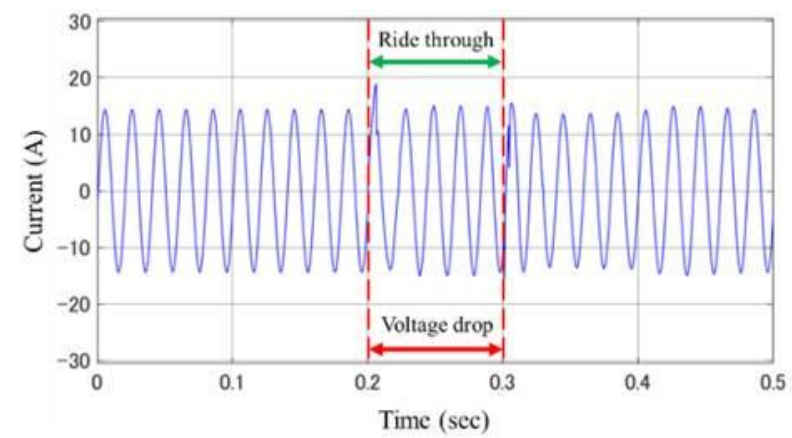

Fig. 19 Current variation during momentary voltage drop with proposed FRT function.

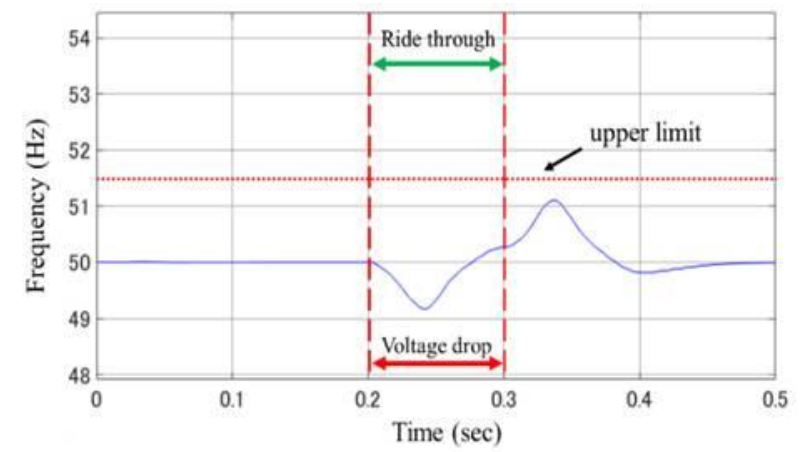

Fig. 20 Frequency variation during momentary voltage drop with proposed FRT function.

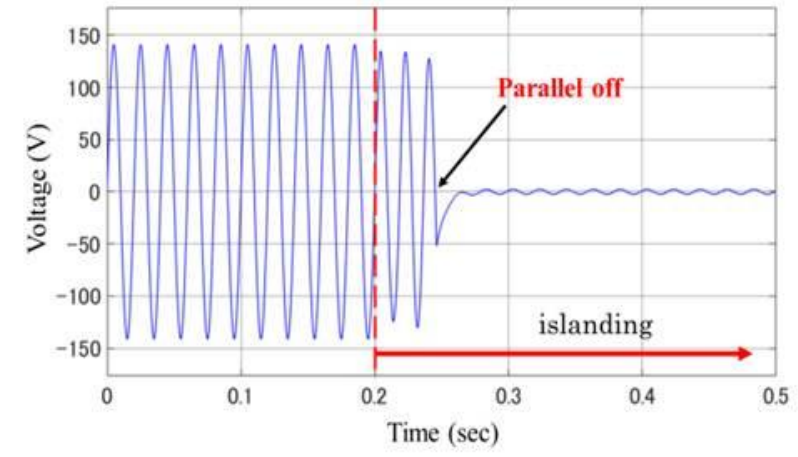

Fig. 21 Voltage variation during islanding with proposed FRT function.

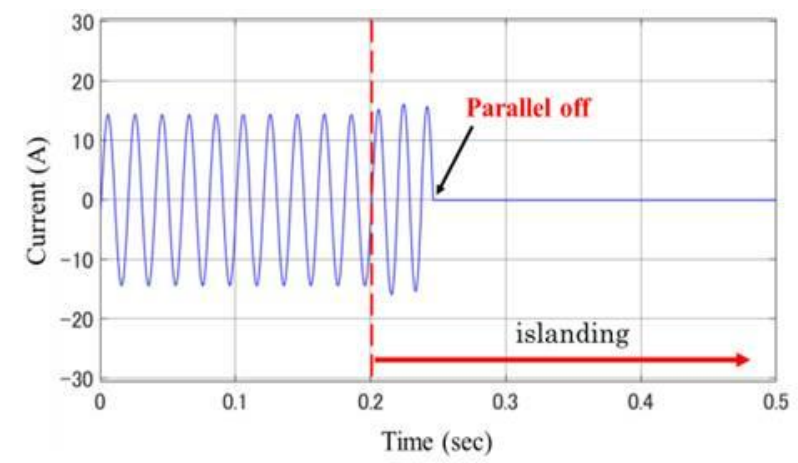

Fig. 22 Current variation during islanding with proposed FRT function.

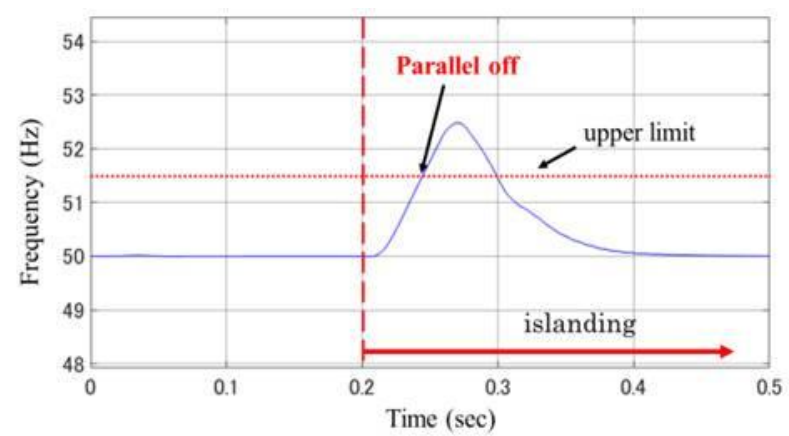

Fig. 23 Frequency variation during islanding with proposed FRT function.

systems using the analytical model of Fig. 14. All three PV systems were implemented the proposed FRT function and the momentary voltage drop occurred. Figs. 24-26 show the simulation results. All PV systems rode through and prevented malfunction that occuring due to the frequency change rate detection method during the momentary voltage drop.

In addition, numerical calculation was carried out in case that only PV system 3 in Fig. 14 was implemented the proposed FRT function and the momentary voltage drop occurred. Figs. 27-29 show the simulation results. As shown in Fig. 28, PV system 1 and PV system 2 malfunctioned and paralleled off during the momentary voltage drop. PV system 3 rode through and prevented malfunction occuring due to the frequency change rate detection method. Since PV system 1 and PV system 2 paralleled off during the momentary voltage drop, the frequency of PV system 3 changed more than the case of all three PV systems with the proposed FRT function.

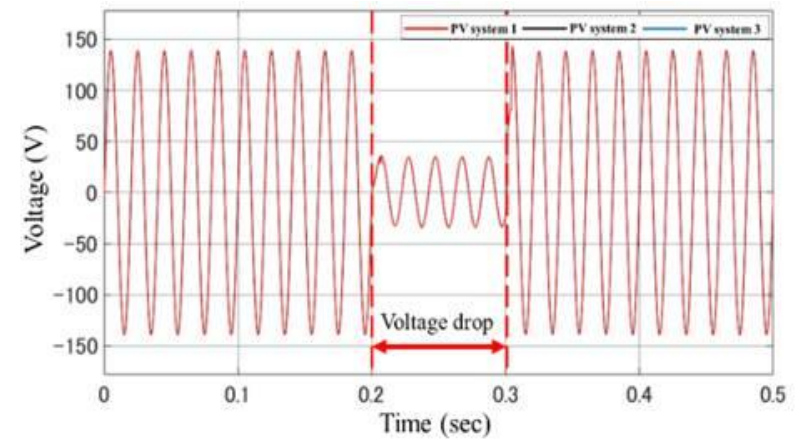

Fig. 24 Voltage variation in case of interconnection of plural PV systems. 


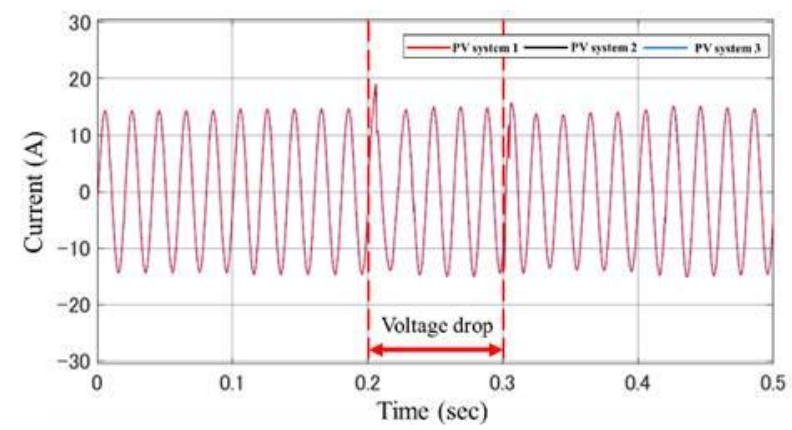

Fig. 25 Current variation in case of interconnection of plural PV systems.

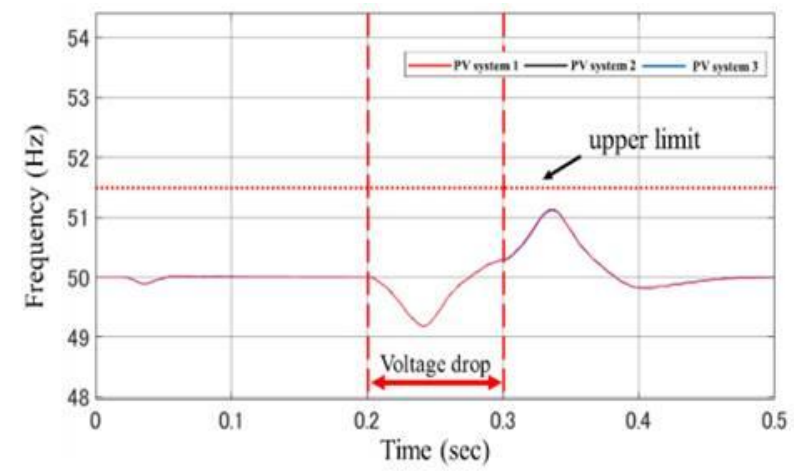

Fig. 26 Frequency variation in case of interconnection of plural PV systems.

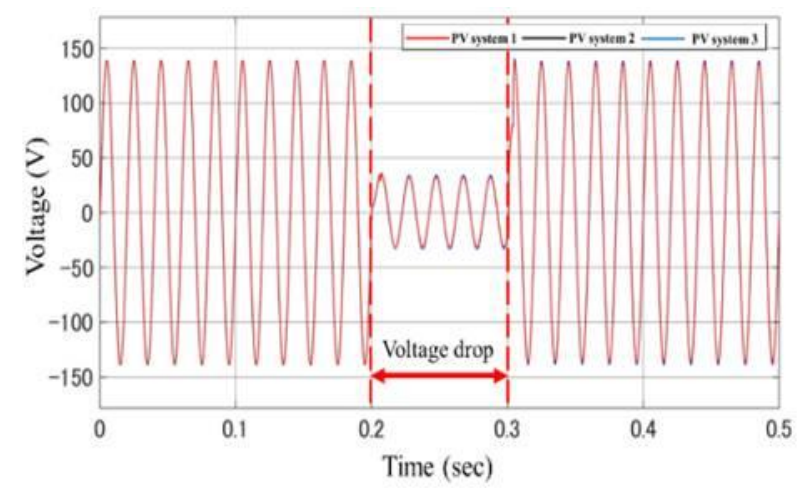

Fig. 27 Voltage variation in case of only PV system 3 is implemented with proposed FRT function.

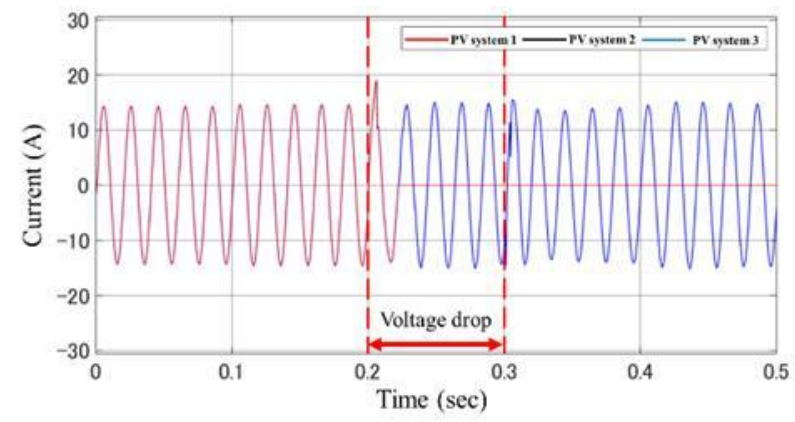

Fig. 28 Current variation in case of only PV system 3 is implemented with proposed FRT function.

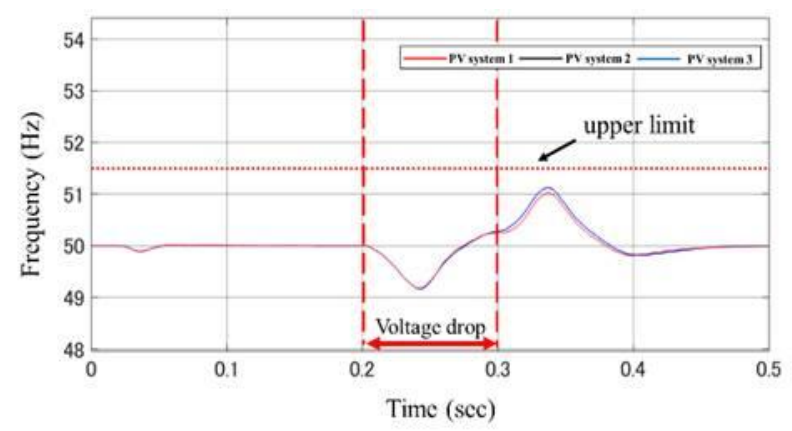

Fig. 29 Frequency variation in case of only PV system 3 is implemented with proposed FRT function.

\section{Conclusions}

In this study, the authors proposed the cooperated control method of the interconnection inverter of PV system with FRT function and islanding detection function that avoids unnecessary stop. In these functions, PV system is paralleled off when the frequency change rate exceeds the threshold consecutively from the standard value of frequency (50 $\mathrm{Hz}$ or $60 \mathrm{~Hz}$ ). PV systems with these proposed functions can ride through and prevent malfunction that is occurred by the frequency change rate detection method during the momentary voltage drop. The authors showed the usefulness of the proposed control method by the numerical calculations.

In the future, the authors will investigate the interaction between the islanding detection function and FRT function during the momentary voltage drop on various conditions. And the authors will implement the proposed method to the actual inverter and will verify the usefulness of the proposed method using experimental equipment.

\section{References}

[1] Kurokawa, K. 2008. "The State-of-the Art of Solar Photovoltaic and Its Future Direction." IEEJ Trans. PE 128 (7): 904-7.

[2] Ishikawa, T. 2006. "Outline of Grid-Interconnection Technologies of Distributed Generation Systems." IEEJ Trans. PE 126 (10): 964-8.

[3] Kobayashi, H. 2009. "Development of Islanding Detection Measure for PV Power Generation to Achieve Stable Operation in Grid Frequency Variation." CRIEPI Research Reports. No. R08013. 
[4] Kai, T. 2015. "Thorough Explanation Illustration Power System Interconnection.” Ohmsha, Ltd.

[5] Endo, H., Takuma, T., Mizukawa, Y., Hayashi, K., and Shinoda, Y. 2016. "Development of Photovoltaic Generation System Line Back $\alpha$ IV." GS Yuasa Technical Report 13 https://www.gs-yuasa.com/jp/technic/vol13/pdf/13_01_0 19.pdf.

[6] Tsutsumi, K., Kimura, R., Sano, M., Taoka, H., Takano, H., and Sakata, T. 2016. "A Study on Influence of
Islanding Detection Time Caused by Response Speed of PV Reactive Power." Annual Meeting of IEEJ 6: 201.

[7] Interconnection of Power System Expert Committee. 2016. "Grid-Interconnection Code JEAC9701-2016." The Japan Electric Association.

[8] Kondoh, J. 2010. "Evaluation on Reduction of Output Suppression Loss by Cooperative Control of Voltage Profile in a Distribution System with a Large Amount of Photovoltaic Power Generation." IEEJ Trans. PE 130 (11): 981-8. 